\title{
A comparison of cycloplegic and manifest refractions on the NR-1000F (an objective Auto Refractometer)
}

\author{
BARUN KUMAR NAYAK, SUPRIYO GHOSE, AND JAI PAL SINGH \\ From the Dr Rajendra Prasad Centre for Ophthalmic Sciences, All India Institute of Medical Sciences, \\ Ansari Nagar, New Delhi-110029, India
}

SUMmaRY The manifest (dry) and cycloplegic refractions of 50 eyes of 25 patients aged 8 to 28 years were studied on the Nikon Auto Refractometer NR-1000F (AR) and compared with the results of clinical refraction (CR) under homatropine and the final clinical acceptance on postmydriatic testing. Only patients in the younger age groups with low to moderate refractive errors were included in this study; high myopes and hypermetropes and patients with aphakia and mixed astigmatism were excluded. The degree of agreement for spherical equivalents, sphere components, and cylinder components was analysed separately for both cycloplegic and manifest refractions on the AR and CR. The results showed that the fixation target in the NR-1000F induces significant instrument myopia during manifest refraction in the younger patients with lower refractive errors. We recommend that caution should be exercised in interpreting manifest refractions on the AR, especially in younger patients. A cycloplegic automatic refraction would be acceptably accurate.

In a previous study ${ }^{1}$ the manifest (dry) refraction of 165 eyes of 86 patients, aged 6 to 75 years, was studied on the Nikon Auto Refractometer NR-1000F. The results obtained were compared with those from clinical refraction and analysed for degree of agreement of various refractive components in different types and grades of refractive errors in the separate age groups. ${ }^{1}$

Though determination of the cylinder axis was found to be very reliable on the NR-1000F Auto Refractometer (AR), the spherical and cylindrical components and the spherical equivalents were observed to skew towards more minus (or less plus), especially so in emmetropes, low hypermetropes, and low myopes. This error in manifest refraction on the AR was observed to decline with increasing age over 40 years, and it was also significantly lower in aphakia and mixed astigmatism. ${ }^{1}$

It thus seemed that in spite of the obvious utility of the device its inbuilt automatic fogging system does not adequately neutralise the patient's accommodative efforts, the fixation target probably inducing significant instrument myopia. ${ }^{1}$ Hence to test our

Correspondence to Dr Supriyo Ghose, Dr Rajendra Prasad Centre for Ophthalmic Sciences, All India Institute of Medical Sciences, Ansari Nagar, New Delhi-110029, India. suspicions we undertook the present study comparing the clinical and AR data on eyes under the effect of cycloplegia.

\section{Materials and methods}

The principles and steps of operating the NR-1000F Auto Refractometer have been outlined previously. ${ }^{1}$ Further operating and maintenance information is given in the manufacturer's instruction manual.

A total of 50 eyes in 25 patients were selected for this comparative analysis. Their ages ranged from 8 to 28 years (Table 1). Except for only two patients who were medical staff, all the other patients in the study were those attending the outpatient department of our hospital for refractive problems. Only patients in the younger age groups with low to moderate refractive errors were included; high myopes and hypermetropes, and patients with aphakia and mixed astigmatism were excluded.

All refractions on the AR were performed with and without the effect of cycloplegia. The cycloplegic used was adequate instillation of homatropine $2 \%$ drops in all the eyes. Clinical refractions were carried out under cycloplegia only, together with a subjective acceptance determined under homatropine. A post- 
Table 1 Distribution of 25 patients (50 eyes) by refractive error and age

\begin{tabular}{llllll}
\hline $\begin{array}{l}\text { Age } \\
\text { group } \\
\text { (years) }\end{array}$ & $\begin{array}{l}\text { No. of } \\
\text { patients }\end{array}$ & \multicolumn{2}{l}{$\begin{array}{l}\text { Type of refractive error } \\
\text { (no. of eyes) }\end{array}$} & $\begin{array}{l}\text { No. of } \\
\text { eyes }\end{array}$ \\
\cline { 2 - 6 } & & Myopia & $\begin{array}{l}\text { Hyper- } \\
\text { metropia }\end{array}$ & Emmetropia \\
\hline$<10$ & 1 & 2 & 0 & 0 & 2 \\
$11-20$ & 14 & 12 & 8 & 8 & 28 \\
$21-30$ & 10 & 6 & 2 & 12 & 20 \\
Total & 25 & 20 & 10 & 20 & 50 \\
\hline
\end{tabular}

mydriatic test was undertaken a week later in accordance with the guidelines routinely followed in clinical refractive practice.

The final prescriptions were based on the objective and subjective clinical data under homatropine and the subjective acceptance by the patient in the postmydriatic test.

The subjective acceptance determined clinically under cycloplegia (CRc) was compared with the AR printout data also under cycloplegia (ARc). The manifest refraction AR printout data (ARm) were similarly matched with the final clinical prescription $(\mathrm{CRm})$. The ARm-ARc and $\mathrm{CRm}-\mathrm{CRc}$ were also calculated for the various refractive components.

The refractive errors in all the eyes were determined clinically as well as on the AR but, as in our previous study, ${ }^{1}$ not necessarily by the same examiner. Whenever both the tests were conducted by the same person, the clinical refraction was invariably done first, so as to obviate any possible examiner bias in the clinical refractive data.

A minimum of three AR readings were obtained for each eye tested, and the reading with the maximum confidence value in each eye was selected for comparison. Readings with a confidence value of less than 90 were rejected as advised in the operating manual instructions.

\section{Results}

The distribution of all the 25 patients by refractive error and age is given in Table 1. Eleven were males and 14 females.
The cylinder axis data determined on AR were as clinically reliable and accurate as found in our previous study on manifest refraction. ${ }^{1}$ Hence the detailed comparative analysis for degree of agreement for cylinder axis is not presented any further.

The mean differences and standard deviations (SD) between Auto Refractometer (AR) and clinical refraction (CR) readings in spherical equivalent data, sphere components, and cylinder components are shown in Table 2, both under cycloplegia and manifest conditions separately. The percentage agreements for the different refractive components are analysed in Table 3, again separately for the cycloplegic and manifest refractions.

The means of the differences between ARm and $A R c$, and $C R m$ and $C R c$, for the various refractive components are evaluated in Table 4.

\section{Discussion}

As our present study has confirmed our earlier observations on the reliability of cylinder axis readings on the AR with or without cycloplegia, we have omitted the presentation of these data, and have focused our attention here on the spherical and cylindrical power data under manifest and cycloplegic conditions.

Our observations in this younger age group depicted in Tables 2 and 3 amply bear out our earlier suspicion $^{1}$ that the inbuilt automatic fogging system of the NR-1000F fails adequately to neutralise the patient's accommodative efforts during manifest refraction, though this problem declined with increasing age over 40 years and hardly existed in aphakia, mixed astigmatism, and higher refractive errors-all conditions in which the patient did not wish to or could not accommodate significantly. ${ }^{1}$

Perrigin et al. ${ }^{2}$ had also suggested that the inclusion of younger subjects would lower the extent of agreement between the clinical and automatic refractions on their subjective refractometer (SR III). Another study ${ }^{3}$ of the effect of cycloplegia on the determination of refractive error by an objective autorefractometer (Ophthalmometron) did not show instrument myopia to be significant. Our clinical refractive

Table 2 Mean differences and standard deviations between Auto Refractometer and clinical refractive data (50 eyes)

\begin{tabular}{|c|c|c|c|c|c|c|}
\hline & \multicolumn{3}{|c|}{ Cycloplegic $(c)$ readings $(A R c-C R c)$} & \multicolumn{3}{|c|}{ Manifest $(m)$ readings $(A R m-C R m)$} \\
\hline & $\begin{array}{l}\text { Spherical } \\
\text { equivalent } \\
\text { (D) }\end{array}$ & $\begin{array}{l}\text { Sphere } \\
\text { component } \\
\text { (D) }\end{array}$ & $\begin{array}{l}\text { Cylinder } \\
\text { component } \\
\text { (D) }\end{array}$ & $\begin{array}{l}\text { Spherical } \\
\text { equivalent } \\
\text { (D) }\end{array}$ & $\begin{array}{l}\text { Sphere } \\
\text { component } \\
\text { (D) }\end{array}$ & $\begin{array}{l}\text { Cylinder } \\
\text { component } \\
\text { (D) }\end{array}$ \\
\hline Mean* & -0.02 & -0.03 & -0.02 & -0.92 & -0.90 & -0.22 \\
\hline SD & 0.25 & 0.24 & 0.34 & 0.90 & 0.97 & 0.46 \\
\hline
\end{tabular}

*The minus (-) sign indicates more myopia or less hypermetropia on the NR-1000F (AR) than by clinical refraction (CR). 
Table 3 Percentage agreement between Auto Refractometer and clinical refractive data of various refractive components (50 eyes)

\begin{tabular}{|c|c|c|c|c|c|c|c|c|c|}
\hline & \multicolumn{3}{|c|}{ Spherical equivalent (D) } & \multicolumn{3}{|c|}{ Sphere component (D) } & \multicolumn{3}{|c|}{ Cylinder component (D) } \\
\hline & $\pm 0 \cdot 25$ & \pm 0.5 & $\pm 1 \cdot 0$ & $\pm 0 \cdot 25$ & \pm 0.5 & $\pm 1 \cdot 0$ & $\pm 0 \cdot 25$ & $\pm 0 \cdot 5$ & $\pm 1 \cdot 0$ \\
\hline $\begin{array}{l}\text { Cycloplegic readings (ARc and } \mathrm{CRc} \text { ) } \\
\text { Manifest readings (ARm and } \mathrm{CRm})\end{array}$ & $\begin{array}{l}86 \% \\
32 \%\end{array}$ & $\begin{array}{l}96 \% \\
44 \%\end{array}$ & $\begin{array}{r}100 \% \\
68 \%\end{array}$ & $\begin{array}{l}80 \% \\
34 \%\end{array}$ & $\begin{array}{r}100 \% \\
54 \%\end{array}$ & $\begin{array}{r}100 \% \\
70 \%\end{array}$ & $\begin{array}{l}78 \% \\
64 \%\end{array}$ & $\begin{array}{l}92 \% \\
70 \%\end{array}$ & $\begin{array}{r}100 \% \\
90 \%\end{array}$ \\
\hline
\end{tabular}

Table 4 Mean differences and standard deviations between cycloplegic and manifest refractive data (50 eyes)

\begin{tabular}{|c|c|c|c|c|c|c|}
\hline & \multicolumn{3}{|c|}{ Auto Refractometer $(A R)$ readings $(A R m-A R c)$} & \multicolumn{3}{|c|}{ Clinical refraction $(C R)$ readings $(C R m-C R c)$} \\
\hline & $\begin{array}{l}\text { Spherical } \\
\text { equivalent } \\
\text { (D) }\end{array}$ & $\begin{array}{l}\text { Sphere } \\
\text { component } \\
\text { (D) }\end{array}$ & $\begin{array}{l}\text { Cylinder } \\
\text { component } \\
\text { (D) }\end{array}$ & $\begin{array}{l}\text { Spherical } \\
\text { equivalent } \\
\text { (D) }\end{array}$ & $\begin{array}{l}\text { Sphere } \\
\text { component } \\
\text { (D) }\end{array}$ & $\begin{array}{l}\text { Cylinder } \\
\text { component } \\
\text { (D) }\end{array}$ \\
\hline $\begin{array}{l}\text { Mean* } \\
\text { SD }\end{array}$ & $\begin{array}{r}-1 \cdot 19 \\
0.90\end{array}$ & $\begin{array}{r}-1 \cdot 10 \\
0.91\end{array}$ & $\begin{array}{r}-0.20 \\
0.38\end{array}$ & $\begin{array}{r}-0.32 \\
0.22\end{array}$ & $\begin{array}{r}-0.28 \\
0.22\end{array}$ & $\begin{array}{r}-0.03 \\
0.09\end{array}$ \\
\hline
\end{tabular}

*The minus (-) sign indicates more myopia or less hypermetropia in the manifest readings $(\mathrm{m})$ than cycloplegic readings (c).

results under manifest and cycloplegic conditions show that the difference between CRm and CRc is in broad agreement with the known differences reported earlier by means of conventional techniques. ${ }^{34}$ Theoretically, ARm-ARc should be equal to $\mathrm{CRm}$-CRc. However, the difference between $\mathrm{ARm}$ and $\mathrm{ARc}$ was much higher than $\mathrm{CRm}-\mathrm{CRc}$ in our study, as is clear from Table 4 ('higher' denoting a larger skew towards more minus or less plus). Again, a significant difference was observed between ARm and CRm (Tables 2 and 3), whereas ideally there should not be any difference at all, and ARm should be equivalent to $\mathrm{CRm}$. But, as ARc was virtually identical with CRc (Tables 2 and 3), we cannot but conclude that the fixation target in the NR-1000F induces significant instrument myopia during manifest refraction in the younger patients with lower refractive errors.

We strongly suggest that automatic refractors like the NR-1000F should be used with great caution when determining manifest refractions, especially in younger patients in whom accommodation is more active than in older, for significant instrument myopia may be induced by the device. A cycloplegic refraction in these eyes would afford acceptably accurate baseline refractive data as a guideline for clinical prescription. Of course the manifest readings on the NR-1000F have proved to be much more reliable in cases of aphakia, mixed astigmatism, and high refractive errors, and for the determination of cylinder axes in all cases.

\section{References}

1 Ghose S, Nayak BK, Singh JP. Critical evaluation of the NR-1000F (an objective Auto Refractometer). Br J Ophthalmol 1986; 70: $221-6$.

2 Perrigin DM, Perrigin J, Grosvenor T. A clinical evaluation of the American Optical SR III subjective refractor. Am J Optom Physiol Opt 1981; 58: 581-9.

3 Keech PM. The effect of cycloplegia on the determination of refractive error by the Ophthalmometron. Am J Optom Physiol Opt 1979; 56: 228-30.

4 Borish IM. Clinical refraction. 3rd ed. Chicago: Professional Press, 1970: 717-8.

Accepted for publication 25 March 1986. 